\title{
Impact of Inland Ports on Transport and Economic Balance of Azov-Black Sea Basin of Russia
}

\begin{abstract}
Submitted 24/01/19, 1st revision 26/03/19, 2nd revision 18/05/19, accepted 06/06/19

$$
\text { Troilin V.V., }{ }^{1} \text { Arustamova M.I., }{ }^{2} \text { Arustamov I.A. }{ }^{3}
$$

Abstract:

Purpose: The article investigates the impact of inland (dry) ports on the transport and economic balance of the Azov-Black Sea basin of the Russian Federation to formulate proposals for the creation of an internationally competitive port infrastructure.

Design/Methodology/Approach: In the framework of studying this problem, it seems necessary to conduct a comprehensive analysis of the dynamics and development trends of the ports of the Azov-Black Sea basin of the Russian Federation, to explore the problematic aspects of the development of transport and economic balance in the Azov-Black Sea basin, to analyze the transport and economic aspects of the creation and operation of inland ports, and to make proposals for their implementation within the framework of the main directions of development.

Findings: The study made possible formulating the conclusion that one of the effective ways to increase the capacity of the transport system of the Azov-Black Sea basin could be the creation of inland ports. The implementation of transport technologies using dry ports will increase the efficiency of the transportation process, including with related modes of transport, as well as reduce transport costs and the investment burden on the development and creation of port infrastructure.

Practical implications: The development of theoretical and methodological guidelines to facilitate the introduction of modern approaches into the theory and practice of transport economics will eliminate the operational and tactical level of decision-making in the organization of multimodal transport to optimize the economic interaction of all participants in the transport chain from the consignor to the consignee in the Azov-Black Sea basin.

Originality/Value: The proposals presented solve the issue of eliminating the blocks of rail transport at seaports and the participation of the Russian transport in container traffic.
\end{abstract}

Keywords: Transport and economic balance, inland ports, port infrastructure, seaports.

JEL Code: O18, R40.

Paper Type: Research article in a Special Issue dedicated to Russian Economy.

Section 8. Business and Economic Issues.

${ }^{1}$ D.Sc. in Economics, Professor, Department of Commerce and Logistics, Rostov State

University of Economics, Rostov-on-Don, Russian Federation, profvvt@gmail.com

${ }^{2}$ Postgraduate, Department of Commerce and Logistics, Rostov State University of

Economics, Rostov-on-Don, Russian Federation, arustamovamarina@mail.ru

${ }^{3}$ Postgraduate, Department of Commerce and Logistics, Rostov State University of

Economics, Rostov-on-Don, Russian Federation, igor arustamov@mail.ru 


\section{Introduction}

Challenges and analysis of modern trends in the development of seaports today draw the attention of many scientists and specialists who are trying to offer their own vision of the prospects for the development of the ports of the Azov-Black Sea basin (ABB). After the inclusion of five seaports into the Russian transport system in 2014, Kerch, Sevastopol, Feodosia, Yevpatoria and Yalta, the acquisition of the new status led not only to a change in their working conditions, but also to creating a prerequisite for adjusting the transport and economic balance Azov-Black Sea region. It is important to note that despite the insignificant share of the Crimean ports in the cargo turnover of Russian Azov-Black Sea basin ports, the blocking of transit cargo flows from Ukraine, as well as the construction of a bridge across the Kerch Strait significantly corrects the conditions for the functioning of the port infrastructure of Russia in this region. Fundamental opportunities and a certain need for the redistribution of cargo traffic arise as well as relieving the load on the Novorossiysk Commercial Sea Port (NCSP) by accepting container flows with imported cargo in the port hub of Kerch and their further diversion to the port of Azov, bypassing the NCSP by the river-sea containerships and others.

\section{Analysis of the Dynamics and Development Trends of Russian Azov- Black Sea Basin Ports}

The key problem for this kind of analysis and conducting adequate economically reliable extrapolations is that in the modern period we have fundamentally new conditions for the development of the Crimean ports, the role and importance of which in the conditions of reducing Ukrainian cargo base are transformed. The inclusion of these ports in the transport system of Russia, the increasing role in meeting the domestic needs of the Crimean Peninsula in various types of cargo, as well as changes in the logistics of their movement, taking into account the need for unloading other ports, creates a fundamentally new disposition. And formalized extrapolations there are presented insufficiently correct and reliable from our point of view.

Thus, K. Mekhantseva, while building up an extrapolation of the change in the volume of cargo turnover in the ports of Russia and Crimea relative to the base period of 19962013, indicates that the forecast could be made for no more than 2 periods without taking into account systemic changes of a strategic nature i.e. the annexation of Crimea to Russia (Mehantseva, 2014).

However, from our point of view, it is precisely not taking these system changes into account that does not allow for this kind of extrapolation, since the basic conditions for the formation of a trend are not preserved initially. This is also indicated by a significant reduction in the turnover of the Crimean ports, a decrease in their economic efficiency under the sanctions by the EU and Ukraine. Scientists A. Bykova and E. Rafikova developed a trend models for cargo turnover at the port of Kerch for 2006- 
2016, which were also used to predict this figure until 2020. As the econometric analysis of the models showed, the polynomial model has the highest accuracy (80\%), which also has the highest quality of the trend approximation $(61 \%)$. The predicted values for different models according to the results of the calculations are presented in Figure 1.

Figure 1. Comparison of the forecast values of cargo turnover of the Kerch port for various models (Developed on the basis of Bykova and Rafikova, 2017).

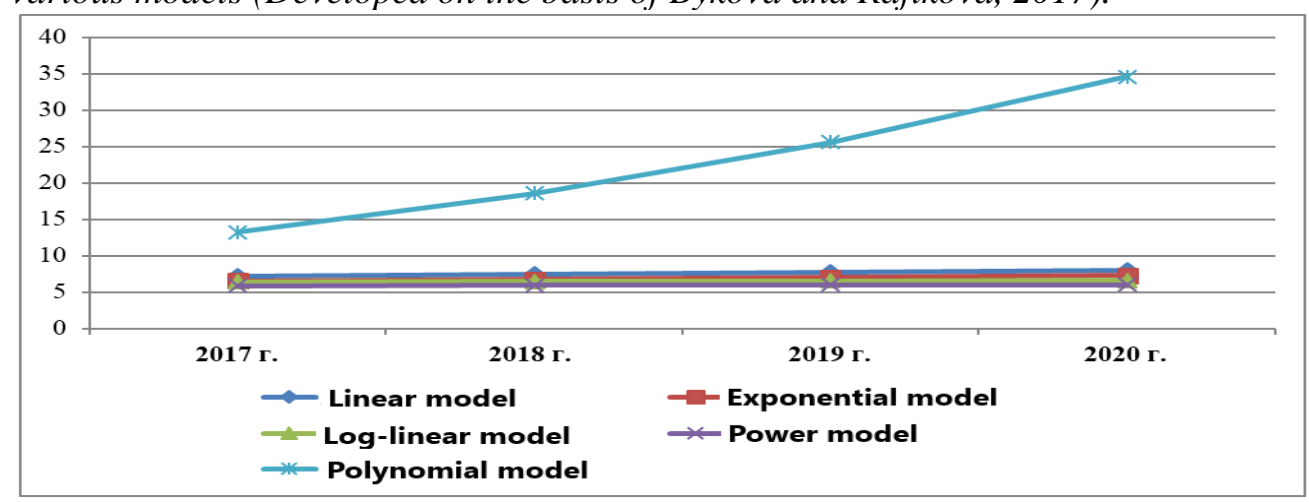

As A. Bykova and E. Rafikova (2017) note, a comparative analysis made possible attributing the polynomial model to the category of optimistic forecasts, and the rest to the category of pessimistic ones. From our standpoint, despite the correctness of this separation from a scientific point of view, it is necessary to formulate at least some arguments that will indicate which model is more relevant in the context of the mobility of the conditions of port infrastructure in Russia and Ukraine in Azov- Black Sea basin.

The complexity of the modern scientific and practical analysis of these issues comes to the fact that its main aspect is more analytical than purely formal (econometric, quantitative). Many conclusions, as well as numerical extrapolations today are extremely difficult due to the fact that the construction of scenarios for the further development of Crimean ports requires formation and justification of a more detailed picture, which should be based on some scenarios for the development of the port infrastructure of Russia, which should be linked to the likely and correct estimated mobility of the geopolitical and geo-economic context in the region.

Otherwise, many generalizations and conclusions will be purely formal; they may contain a constructive message with a complete lack of understanding of the conditions and factors of its realistic implementation. Thus, A. Bykova and E. Rafikova (2017) point out that the main prospect in the construction of a highway through the Kerch Strait is to ensure a significant increase in freight and passenger traffic. However, it is precisely the provision of this significance that forms the sufficiency of the condition for increasing the efficiency of the functioning of the crossing complex through the strait. 
The construction of the Crimean Bridge and the filling of the Crimean ports with cargoes is not the most important and completely solvable part of the overall task, which requires determining how and where these cargoes could be exported. That is, one way or another, the scientific and practical study of this issue rests on the need to take into account the position of Ukraine, which may well prolong the prohibitive measures in relation to transit and further pursue companies that will bring ships to the ports of Crimea. That is, the main problem is not so much the provision of a cargo base as in the organization of transit.

On the other hand, it is important to note that the assessment of the prospects for the development of the Crimean ports today is formulated primarily as a project of Russia and Ukraine, which have not yet reached consensus and do not have sufficient cargo and passenger traffic to pay for the project. The achievement of necessary amounts is possible only if the transition is included in the ring highway around the Black Sea and the Europe-Caucasus-Asia transport corridor (TRACECA). Accordingly, it can be assumed that the issue of such integration into these regional and transcontinental transport and logistics systems is not simple, and at the same time requires large-scale investments in the development of infrastructure for transport approaches that will ensure the functioning of the bridge from both Russia and Ukraine.

This doubles the need to achieve consensus on both sides. The integration into the ITC is not possible without it. Based on this, many speculative constructions, for example, "connect the peninsula with a branch of the main corridor section by sea from the port of Rostov-on-Don to the port of Kerch and from Novorossiysk to the port of Kerch, or by land - from Novorossiysk to Kerch, and then to Sevastopol" require additional substantiation of the realism of their implementation in the existing conditions (Ignatenko and Fil, 2017).

We believe that the conclusion of scientists that the analysis of the main trends in the development of Russian ports based on aggregated statistical data for the past and future periods allows them to be used in strategic planning for the joint sustainable development of the ports of Crimea and Russia is not accurate enough (Ignatenko and Fil, 2017). Any forecast calculations could only be derived from an analytical scenario study of the conditions for the further development of the port infrastructure of Russia in the Azov-Black Sea basin, the development of Ukrainian ports, the geopolitical position of the latter and options for a balanced redistribution of the cargo base between Russian ports in the region.

\section{Challenges of of the Development of Transport and Economic Balance in the Azov-Black Sea Basin}

Any attempt to compare the forecast trend values and forecast values from the Transport Strategy of the Russian Federation until 2030, the cargo turnover figures of the Russian ports of the Black Sea basin is not entirely correct for several reasons: 
- The strategy was developed out from the assumption that the Crimea will be annexed to Russia, which causes systemic changes in the work of the port infrastructure in this region. In turn, the forecast calculations include such a condition;

- predictive calculations are made on the basis of simple correlation smoothing and extrapolation of the trend based on the regression built for the past period, the patterns of which will not have a sufficiently close correlation with the patterns determining the perspective trend that actually develops in other conditions of the already attached Crimea and a number of economic and political complications for Russia;

- the use of a correlation-regression equation in the context of changes in basic factors and conditions for the development of the port infrastructure of Russia in the region seems to be economically incorrect from a substantive point of view.

In our opinion, reducing the transit cargo turnover and the need to increase it in the framework of various development scenarios and geopolitical decisions on the part of Russia and Ukraine create a high level of variability in scientific and practical development and trend forecasting of cargo turnover in the ports of Crimea. Here we should proceed not from pessimistic and optimistic scenarios but use a certain economic understanding of actions that will precede the implementation of any of the scenarios that should receive adequate econometric formalization at the level of predictive calculations.

Normalization of relations with Ukraine and the resumption of transit cargo flows through its territory, the inclusion of the peninsula in the branch of the main section of the TRACECA corridor - all these are quite succinct decisions that will entail a significant redistribution of the cargo base in the structure of Russian ports in the basin and an increase in its volume as a whole. So, we can state the presence of certain theoretical and methodological features of scientific and practical development and forecasting, numerical measurement of the development trends of the Crimean ports of Russia in the Azov-Black Sea basin.

These features in general reflect the logic of modern numerical empirical analysis of the development dynamics of the Crimean ports and ports of the Azov-Black Sea basin. We note that the empirical assessment of the dynamics of Crimean ports development should proceed from the assumption that for 35 years they were focused on the maintenance of export and transit cargo transported through the territory of Ukraine. Thus, in the modern period, due to the absence in the Crimea of its own cargo base, the dynamic development of ports is possible only in case of building the Kerch Strait bridge.

Currently, the shortage of cargo traffic reduces the profitability of the port facilities due to the increased cost of cargo operations and high cost of services in conditions where the main load of facilities, infrastructure and workers is focused on the organization of the ferry traffic (its cash flow only covers labor costs). 
Hence, it is important to read not just the dynamics, but also the economic efficiency of the current functioning of the Crimean ports, and the potential for their development as they progress through the next stages of integration with the Russian transport system in a new, not very simple status due to sanctions and unfriendly position of Ukraine. In the modern period, the development of the seaports of the Crimea will occur in two stages. At the first (current) stage, before the construction of the transport crossing, a survival strategy will be implemented, which includes reducing the costs of port operations, reconstruction of the freight transport system directly related to the reception of passengers and cargo, implementation of non-core assets.

The second stage involves the active integration of the State Unitary Enterprise "Crimean Sea Ports" into the adsorption of transport flows of the Azov-Black Sea basin. This implies the completion of the reconstruction of the port infrastructure facilities, the marketing policy orientation on cargo flows that are not dependent on the sanctions regime. And attracting private capital on public-private partnership (PPP) terms to the use of port capacities (Sea ports, 2018).

Figure 2. Distribution of cargo transshipment volumes by types in the Azov-Black Sea basin in 2012-2017, mln. tons. (Compiled on the basis of Sea ports, 2018)

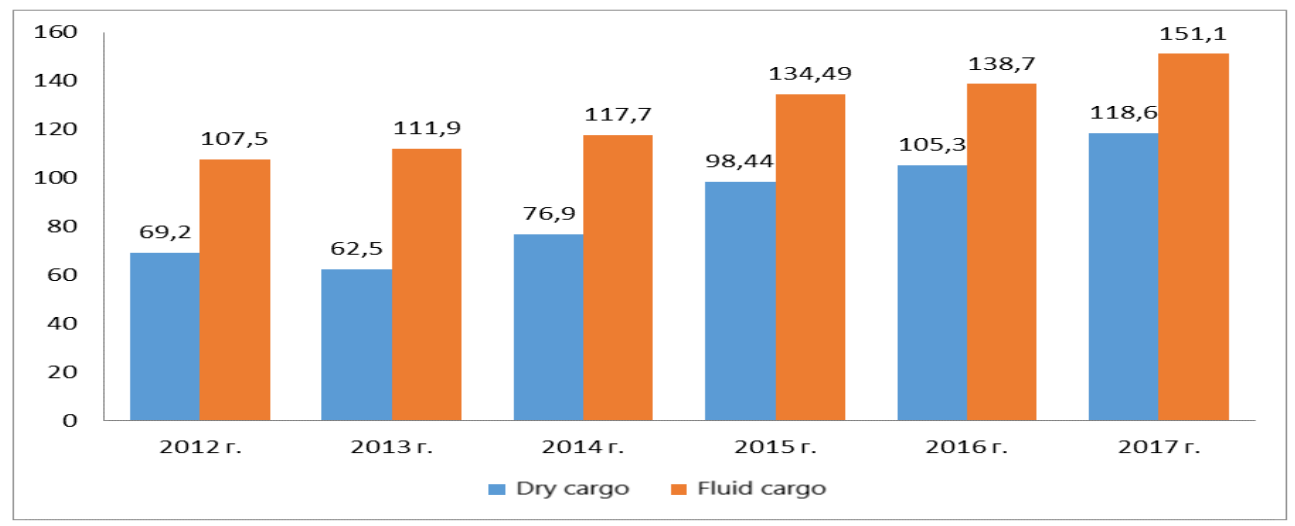

As seen from Figure 2, in 2013-2017 in the region under consideration, there is a steady increase in the volume of cargo handling. At the same time, the volume of transshipment of liquid cargo exceeds the figure for dry cargo. It is important to note that the further development of the port infrastructure of Russia in the Azov-Black Sea basin will be accompanied not only by growth, but also by the redistribution of the cargo base between the ports. The priority of the development of the Crimean ports in comparison with other Russian ports in the Azov-Black Sea basin will be determined by the importance of those in the strategy of the state. From the deeper retrospective, the port infrastructure of the Crimea has always been underfunded. This predetermined a significant imbalance in the dynamics of the growth of bulk and dry cargo in the Azov-Black Sea basin when a significant part of cargo, especially dry 
cargo, was handled in the ports of Ukraine (20-30 mln tons per year), the cargo base of which tends towards the south of Russia .

In the future, this situation could be adjusted as a result of the planned creation of dry ports, which will provide not only transport links with the Crimea, but also allow the formation of an infrastructure base for the further development of transport and logistics capacities of the Azov-Black Sea basin.

\section{Transport and Economic Aspects of the Creation and Operation of Inland Ports}

Major Russian seaports were designed and created more than 50 years ago, taking into account their cargo turnover, technical equipment with loading and unloading equipment and standard sizes of ships of that time (Novorossiysk, Tuapse). At the same time, some ports were territorially formed much earlier (Taganrog, Azov). As a result of the expansion of urban agglomerations, the ports were surrounded by residential structures, which currently hinders their expansion and, consequently, hinders cargo turnover. In addition, in some cases, transferring them to another place is inexpedient and not possible not only by economic criteria, but also by climatic and geographical conditions posing requirements on the terrain, temperature conditions of water, approach depths. The construction of the seaport as a hydraulic structure also requires significant costs, which are currently impossible due to the economic crisis and sanctions against Russia. These phenomena are peculiar not only to the domestic port business, but also reflect global trends.

Currently, more than 10 dry ports have been created in the Russian Federation. Their development and functioning are hampered by the lack of economically substantiated developments that consider the experience of both domestic science and practice and the experience of foreign countries. In addition, a comprehensive synthesis of dry ports functioning on one interdisciplinary (economic) platform, combining the interests of stevedoring, freight forwarding, logistics companies, the state, carriers and cargo owners, is required, since it is the approach allowing them to work effectively. And taking into account the specifics of the functioning of sea transport, which provides more than $80 \%$ of freight traffic in international traffic, the task is to coordinate the activities of dry and sea ports as two important components of a transport system whose solution will help to increase the freight and throughput capacity of maritime transport in the Russian Federation.

Moreover, inland ports are a comprehensive solution for ensuring the interaction of rail and sea transport, which allows storing cargoes, processing them with the provision of services on value creation, customs clearance, consolidation by ship lots and directions of transportation. Implementation of transport technologies using inland ports will increase the capacity of seaports, improve the efficiency of the transportation process, (and, importantly, with related modes of transport), reduce 
transport costs and the investment burden on the development and creation of port infrastructure.

General directions for the development of dry ports are presented in Section VII "Stages of development of the transport system" of the Transport Strategy of the Russian Federation for the period until 2030 (Transport Strategy of the Russian Federation for the period until 2030). Their implementation needs the following:

- explore the modern meaning of the concept of "inland port" taking into account the Russian and international experience of its use;

- analyze the status of the transportation activities of maritime transport of the Russian Federation;

- perform the classification of inland ports according to various criteria;

- develop measures to improve the efficiency of dry port management;

- develop methodological, scientific and practical recommendations for determining the development strategy for dry ports in the Russian Federation;

- identify the features of the functioning of dry ports in the framework of intermodal transport and logistics systems;

- offer an economic mechanism for the practical implementation of projects for the creation of dry ports in large transport hubs;

- analyze the economic and legal regulation of the functioning of dry ports;

- develop criteria for determining the level of transport and economic compatibility of inland and seaports.

\section{Conclusion}

In our opinion, the development of theoretical and methodological provisions facilitating the introduction of modern approaches into the theory and practice of transport economics will solve the above problems and eliminate the problems of the operational and tactical level of decision-making in the organization of multimodal transport to optimize the economic interaction of all participants in the transport chain from the consignor to the consignee in $\mathrm{ABB}$ with a decrease in delivery time and price for transportation. Also, this solves the urgent issue of eliminating the "congestion" of rail transport at seaports and the participation of the Russian transport system in container traffic within the framework of international transport corridors based on multimodal technologies.

\section{References:}

Bykova, A.D., Rafikova, E.R. 2017. Analysis of the development trends of the ports of the Crimea, taking into account the strategic infrastructure solutions of the Russian Federation. Proceedings of Transport and Logistics: Innovative Development in the Context of Globalization of Technological and Economic Relations, RSTU publ., Rostov-on-Don, 79. 
Ignatenko, O., Fil, A. 2017. Statistical analysis of the turnover of the Azov-Black Sea basin after the annexation of the Crimea. Proceedings of conference "Transport and logistics: innovative development in the context of globalization of technological and economic relations", RSTU publ., Rostov-on-Don, 125.

Mehantseva, K.F. 2014. On the possibilities of comparable strategic planning for joint sustainable development of the ports of the Black Sea basin of Russia and the Crimea. Bulletin of Rostov State University of Economics, 4(48), 36.

Sea Ports. 2018. All shipments of Russia. Overview of the transport of goods through the seaports of Russia, the Baltic States, Ukraine for 2017, 1(162), 57.

Transport of Crimea. 2016. Cautious growth and constraints. Sea news of Russia, 4, available at: http://www.morvesti.ru/analitics/detail.php?ID=62550\&sphrase_id=394240.

Transport strategy of the Russian Federation for the period up to 2030. 2008. Available at: http: //www.garant.ru/products/ipo/prime/doc/94460/. 